\title{
Determinação do teor de proteína em genótipos de feijão comum cultivados em diferentes níveis de nitrogênio
}

\section{Determination of protein content in common bean genotypes cultivated in different levels of nitrogen}

\author{
Rodrigo Ribeiro Fidelis'(*) \\ Fabricio Henrique Moreira Salgado \\ Cássia Mara dos Santos Alexandrino 3 \\ Taynar Coelho de Oliveira Tavares ${ }^{4}$ \\ Raphael Campestrini ${ }^{5}$
}

\section{Resumo}

Objetivou-se, com este trabalho, avaliar a qualidade nutricional de 40 genótipos de feijão comum cultivados em diferentes níveis de nitrogênio $(\mathrm{N})$ no sul do Estado do Tocantins. Foram feitas determinações dos teores de nitrogênio e de proteína de grãos de feijão, obtido de experimentos sob alto e baixo nível de nitrogênio conduzidos a campo, na estação experimental da Univesidade Federal do Tocantins. A semeadura foi realizada no dia 12 de junho de 2010, formado por dois experimentos. Os grãos foram armazenados em temperatura ambiente por um prazo de nove meses após a colheita; depois desse período os grãos foram levados até o laboratório de solos da Universidade Federal do Tocantins, localizado no campus Universitário de Gurupi, sendo as amostras separadas e moídas. Para avaliar os teores de nitrogênio $(\mathrm{N})$ e proteína bruta $(\mathrm{PB})$, presentes no grão, foi utilizado o método Kjeldahl. Houve variabilidade genética para teor de proteína nas diferentes doses de Nitrogenio $(\mathrm{N})$ aplicadas. $\mathrm{O}$ ambiente com maior dose de $(\mathrm{N})$ proporcionou maior teor de proteína no grão. O cultivar IPR Corujinha é recomendado quanto a seu teor de proteína bruta para ser cultivado e consumido por agricultores com

1 Dr.; Fitotecnia; Universidade Federal de Viçosa, UFV, Brasil; Professor Associado da Universidade Federal do Tocantins e Bolsista de Produtividade em Pesquisa CNPq; Endereço: Universidade Federal do Tocantins, Campus Universitário de Gurupi. Rua Badejós, chácaras 69 e 72, Lt 07.Zona Rural, CEP: 77402-970 - Gurupi, TO - Brasil; E-mail: fidelisrr@uft. edu.br $(*)$ Autor para correspondências

2 Dr.; Agronomia; Universidade Federal de Goiás, UFG, Brasil; Engenheiro Agrônomo da Agência de Defesa Agropecuária do Estado do Tocantins - ADAPEC; Endereço: Unidade Seccional de Cariri do Tocantins. Avenida Bernado Sayão. Centro, CEP: 77453000 - Cariri do Tocantins, TO - Brasil; E-mail: fabriciogpi@hotmail.com

3 Engenheira Agrônoma; Universidade Federal do Tocantins, UFT, Brasil; E-mail: cassiamarauft@ hotmail.com

4 Dra.; Produção Vegetal; Universidade Federal do Tocantins, UFT, Brasil; Professora da disciplina de Seminários II na Pós-Graduação em Produção Vegetal-UFT; Endereço: Universidade Federal do Tocantins, Campus Universitário de Gurupi. Rua Badejós, chácaras 69 e 72, Lt 07. Zona Rural, CEP: 77402-970 - Gurupi, TO; E-mail: taynarcoelho@ hotmail.com

5 Mes.; Produção Vegetal; Universidade Federal do Tocantins, UFT, Brasil; E-mail: campestrini.r@hotmail.com

Recebido para publicação em 05/01/2016 e aceito em 22/04/2019

\begin{tabular}{llllll}
\hline Ambiência & Guarapuava (PR) v.I5 n.I & p. I6I - I72 & Jan/Abr 20I9 & ISSN I808 - 025I
\end{tabular}


pouca tecnologia, pois é capaz de apresentar boa qualidade nutricional mesmo cultivado sob estresse. Os cultivares Aporé, BRS Marfim e Diamante Negro apresentam elevada qualidade nutricional quando cultivados em ambiente ideal.

Palavras-chave: Phaseolus vulgaris L.; segurança alimentar; proteína; nutrição.

\section{Abstract}

This study aimed to evaluate the nutritional quality of 40 genotypes of common bean cultivated in different levels of nitrogen $(\mathrm{N})$ in the south of Tocantins State. Determinations of nitrogen content and bean protein were made, gotten from experiments under high and low level of nitrogen conducted in field, in the experimental station of the Federal University of Tocantins. Seeding was carried out on June $12^{\text {th }}$ of 2010, consisting of two experiments The grains had been stored at room temperature for nine months after the harvest, and then the grains were taken to the Soils Laboratory of the Federal University of Tocantins, located at the Academic campus of Gurupi, the samples being separated and ground. The Kjeldahl method was used to evaluate the levels of nitrogen $(\mathrm{N})$ and crude protein $(\mathrm{PB})$ present in the grain. There was genetic variability for nitrogen content and protein in different doses of Nitrogen applied, the environment with higher Nitrogen dose provided higher protein content in the grain, the cultivar IPR Corujinha is recommended due to its crude protein content to be cultivated and consumed by farmers with little technology, because it is able to present good nutritional quality even cultivated on stress. The cultivars Aporé, BRS Marfim and Diamante Negro present high nutritional quality when cultivated in ideal environment.

Key-words: Phaseolus vulgaris L.; food security; protein; nutrition.

\section{Introdução}

As fontes de proteína de origem vegetal têm sido amplamente utilizadas para a alimentação humana, em razão do baixo custo e menor teor de gordura, quando comparados aos alimentos de origem animal. O feijão (Phaseolus vulgaris L.) apresenta cerca da metade do teor de proteína bruta em relação à soja, porém, é de maior digestibilidade protéica, com cerca de 78,70\% (PIRES et al., 2006). O consumo diário de feijão é saudável devido à qualidade da proteína e ao alto teor de minerais (RIBEIRO et al., 2007; RIBEIRO et al., 2008). Essas características tornam o feijão comum uma alternativa para suprir as necessidades de proteína na alimentação humana.

A espécie Phaseolus vulgaris L., conhecida popularmente como feijão comum, pertence à família Leguminosae e subfamília Papilionoidae e é uma das principais fontes de proteína vegetal consumida no Brasil (BURATTO et al., 2009). É uma leguminosa consumida em grande quantidade no Brasil e no mundo, por todas as classes sociais, sendo, para muitos indivíduos, a principal fonte de proteínas, minerais, vitaminas e fibras (DEL PINO e LAJOLO, 2003). As propriedades nutritivas do feijão comum baseia-se no fato de ela ser uma fonte rica de proteína, de carboidratos complexos de baixo índice glicêmico e pobre em gordura (PEREIRA, 2008).

O Brasil é o maior produtor e consumidor mundial de feijão-comum (Phaseolus vulgaris L.), com uma produção de cerca de 2,8 milhões de toneladas anuais (FAO,2014). De acordo com Conab (2014), a produtividade média nacional e do Estado do Tocantins na safra 2013/2014, 
foi de 1.033 e $833 \mathrm{~kg} \mathrm{ha}{ }^{-1}$, respectivamente. Entretanto, Salgado et al. (2011) e Salgado (2011) obtiveram rendimentos superiores, com médias variando de 1.348 a $3.132 \mathrm{kgha}^{-1}$. A melhoria no nível tecnológico é fundamental para aumentar a produtividade do feijoeiro, como o uso de sementes de alta qualidade (GOMES JUNIOR E SÁ, 2010), cultivar, época de plantio, espacamento, manejo fitossanitário e nutricinal, adubação, entre outros.

Dentre esses incrementos destaca-se o nitrogênio $(\mathrm{N})$, o qual estimula o crescimento vegetativo das plantas, além de contribuir com alto potencial produtivo. O nutriente absorvido em maior quantidade pelo feijoeiro é o nitrogênio (CANTARELLA, 2007), sendo também o nutriente mais exigido pela cultura do feijoeiro, constituinte essencial de aminoácidos, enzimas, nucleotídeos e muitos outros compostos vegetais (MARENCO; LOPES, 2009; FAGAN et al., 2007), sendo responsável pelo aumento da área foliar, que aumenta a eficiência de intercepção da radiação solar e a taxa fotossintética e, consequentemente, a produção (FAGERIA et al., 2003; FAGERIA e BALIGAR, 2005).

Dessa forma, o uso racional da adubação nitrogenada é de suma importancia, pois aumenta a eficiência de radiação, refletindo em maior valor nutricional (FAGERIA et al., 2003). O alto custo de fertilizantes nitrogenados tem despertado interesse de estudo com genótipos quanto à adubação nitrogenada e à resposta quanto aos valores de proteínas. Esse atributo é determinado pelo genótipo e influenciado pelo ambiente durante o desenvolvimento da cultura (LEMOS et al., 2004).

$\mathrm{Na}$ literatura, há evidências de que, além da própria cultivar, o conteúdo proteico dos feijões pode ser influenciado por fatores climáticos, local de cultivo, além da interação Genótipo versus Ambiente (GOMES JÚNIOR et al., 2005; BURATTO et al., 2009). De modo similar, observase a influência desses efeitos para o tempo de cocção dos grãos (BORDIN et al., 2010; PERINA et al., 2010). O feijão comum é consumido na forma de vagem verde, grãos verdes, grãos secos ou para preparar pratos (LANARO et al., 2011), tornando o feijão um alimento básico para as populações de baixa renda, servindo, também, como emprego e fonte de renda (FROTA et al., 2010). Além de ser considerado a principal fonte de proteínas da população de menor poder aquisitivo, o feijão apresenta, ainda, como vantagem, a possibilidade de cultivo em diferentes épocas do ano, em períodos definidos como safras "das águas", "da seca" e "de inverno" (AFONSO et al., 2011). Estudo realizado por Gomes Junior et al. $(2005$; 2010) verificaram que o incremento nas doses de nitrogênio, propiciaram maior acúmulo de proteína bruta na semente de feijão comum.

$\mathrm{O}$ objetivo de avaliar a qualidade nutricional de 40 genótipos de feijão comum cultivados em dois níveis de nitrogênio, no sul do estado do Tocantins, e obter informações da influencia da adubação nitrogenada nos teores de proteínas, para que ela possa ser recomendada a pequenos produtores na agricultura de subsistência.

\section{Material e Métodos}

Foram conduzidos dois experimentos na Estação Experimental de Pesquisa, pertencente ao Campus Universitário de Gurupi-TO, na Universidade Federal do Tocantins (UFT), localizado a latitude $11^{0} 43^{\prime} 45^{\prime}$ 'S e longitude 490 04'07'W, altitude de $280 \mathrm{~m}$. Cada experimento (alto e baixo nível de nitrogênio) foi conduzido no delineamento em blocos ao acaso com quatro repetições. A semeadura foi realizada no dia 12 de junho de 2010. Utilizou-se a mesma densidade populacional para todos os 40 genótipos. A parcela experimental foi constituída por quatro linhas de 4,0 $\mathrm{m}$ de comprimento, espaçadas de $0,45 \mathrm{~m}$, resultando numa população de 266.666 plantas por hectare. 
Realizou-se a análise química do solo, que apresentou os seguintes resultados: $\mathrm{Ca}$ (cmolc $\left.\mathrm{dm}^{-3}\right): 3,6 ; \mathrm{Mg}\left(\mathrm{cmolc} \mathrm{dm}^{-3}\right): 1,4 ; \mathrm{K}\left(\right.$ cmolc dm $\left.^{-3}\right): 0,1 ; \mathrm{SB}\left(\mathrm{cmolc} \mathrm{dm}^{-3}\right): 5,1 ; \mathrm{Al}\left(\mathrm{cmolc} \mathrm{dm}^{-3}\right.$ $\left.{ }^{-3}\right): 0,0 ; \mathrm{H}+\mathrm{Al}\left(\mathrm{cmolc} \mathrm{dm}^{-3}\right): 4,7 ; \mathrm{P}-$ melich $\left(\mathrm{mg} \mathrm{dm}^{-3}\right): 1,1 ; \mathrm{T}\left(\mathrm{cmolc} \mathrm{dm}^{-3}\right): 9,8 ; \mathrm{V}(\%): 52 ; \mathrm{M} . \mathrm{O}$ (\%): 2,0. Para definir a dose ideal e baixa de nitrogênio desse experimento, consideraram-se outros estudos avaliandos diferentes doses de nitrogênio no feijão.

A adubação de plantio foi realizada com base na análise de solo e nas recomendações para cultura do feijão comum, com relação à adubação nitrogenada realizada. No primeiro experimento que simulou ambiente com baixo teor de $(\mathrm{N})$ foram aplicados $20 \mathrm{~kg} \mathrm{ha}^{-1}$ de $\mathrm{N}$ no plantio sendo o nutriente proveniente da fonte superfosfato amoniacal (03-17-00). No segundo experimento que simulou ambiente com alto teor de nitrogênio foram aplicados $120 \mathrm{~kg} \mathrm{ha}^{-1} \mathrm{de} \mathrm{N}$, sendo $20 \mathrm{~kg}$ $\mathrm{ha}^{-1}$ aplicado na semeadura proveniente da adubação fosfatada e $100 \mathrm{~kg} \mathrm{ha}{ }^{-1}$, na forma de ureia, aplicado em cobertura e parcelado em duas vezes, sendo a primeira aos 15 dias e a segunda aos 30 dias após a emergência da cultura, conforme recomendação de Rosolem e Marubayashi (1994).

Após a colheita os grãos foram armazenados em temperatura ambiente por um prazo de nove meses, depois desse período os grãos foram levados até o laboratório de solos da Universidade federal do Tocantins, Campus Universitário de Gurupi-TO onde foram separado quatro amostras de cada genotipo e moídas em moinho tipo Willey, para realização das análises.

Para avaliar os valores de nitrogênio e proteína bruta $(\mathrm{PB})$ presentes na semente de feijão comum, foi utilizado o método clássico Kjeldahl. Que compreende as etapas: digestão, destilação e titulação das amostras (YASUHARA e NOKIHARA, 2001). Pesou-se 0,2g da amostra e transferiu para o balão digestor de kjeldahl, em seguida foi acrescentado 0,02g de uma mistura catalizadora e $5 \mathrm{~mL}$ de ácido sulfúrico concentrado, sendo levado ao bloco digestor a $400^{\circ} \mathrm{C}$, por quatro horas, a mistura apresento-se semelhante a um líquido claro. Após esfriar, foi adicionado ao balão digestor cerca de $5 \mathrm{~mL}$ de água destilada, cuidadosamente e, em seguida, procedeu-se à destilação com solução de NAOH e acido bórico. Após processo de destilação, foi feita a titulação com solução padrão de $\mathrm{HCl} 0,1 \mathrm{~N}$, com fator conhecido, através da fatoração tris, até ponto de viragem do indicador. Para converter o nitrogênio medido e obter o valor de proteína nos grãos de feijão comum, foi multiplicado o conteúdo de nitrogênio por um fator arbitrário, que representa um fator médio para o material em estudo, que foi de 6,25.

Os dados experimentais foram submetidos a análises individual e conjunta de variância, com aplicação do teste F. A análise conjunta foi realizada sob condições de homogeneidade das variâncias residuais, uma vez que a relação entre os quadrados mendios é menor que 7. Para as comparações entre as médias dos tratamentos, foram utilizados os testes Tukey e Scott-Knott, ambos a 5\% de probabilidade, utilizando-se o aplicativo computacional SISVAR (FERREIRA, 2011).

\section{Resultados e Discussão}

A análise de variância mostrou efeito significativo da interação entre genótipos e ambientes para as características avaliadas, mostrando que os ambientes influenciam de forma diferenciada no comportamento dos genótipos, sendo, portanto, necessário efetuar o desdobramento dos fatores. Os fatores genótipo e ambiente apresentaram significância para todas as características estudadas, mostrando que existe variabilidade entre os genótipos, bem como, diferença entre os ambientes (Tabela 1). 


\section{Tabela 1 - Resumo da análise de variância, pelo teste $F$, das médias de nitrogênio ( $N$ ) e de proteína bruta (PB) nos grãos de 40 genótipos cultivados em Gurupi-TO, na entressafra de 2010}

\begin{tabular}{cccc} 
& \multicolumn{3}{c}{ Quadrado Médio } \\
\cline { 2 - 4 } FV & GL & $\mathbf{N}(\mathbf{\%})$ & PB (\%) \\
\hline Bloco (AMB) & 6 & $0,023^{\text {ns }}$ & $0,895^{\text {ns }}$ \\
Genótipo & 39 & $0,713^{*}$ & $27,849^{*}$ \\
Ambiente & 1 & $2,324^{*}$ & $90,783^{*}$ \\
Genot/Amb & 39 & $0,528^{*}$ & $20,637^{*}$ \\
Resíduo & 234 & 0,021 & 0,840 \\
Média Geral & & 3,02 & 18,863 \\
CV (\%) & & 4,86 & 4,86 \\
ns não significativo; " significativo para $P \leq 0,01$; " significativo para $P \leq 0,05$ pelo teste $F$. &
\end{tabular}

Analisando o teor de nitrogênio (N), nos grãos dos diferentes genótipos no ambiente de baixo nitrogênio (Tabela 2), constata-se a formação de seis grupos estatísticos, sendo que o de maior teor foi constituído apenas pelo cultivar IPR Corujinha (4,22\%). Pessoa (1998) relatou que teores de $\mathrm{N}$ no grão de feijão, acima de 3,47\%, indica que não há deficiência desse elemento na planta. O segundo grupo foi constituído por oito genótipos, cujos teores de $\mathrm{N}$ variaram de 3,15 a 3,40\%. O terceiro grupo foi constituído por quatorze genótipos com teores variando entre 2,91 a 3,10\%. O quarto grupo foi constituído por treze genótipos com teores variando entre 2,71 a $2,89 \%$. O quinto grupo foi constituído por três genótipos com teores variando entre 2,41 a 2,46\% e o sexto grupo foi formado pelo cultivar IPR-Chopim com 1,93\% de N. A partir do segundo grupo estatístico, os valores obtidos de $\mathrm{N}$, nos grãos de feijão comum, indicam deficiência de $\mathrm{N}$ na planta.

Os valores de $\mathrm{N}$ obtidos em ambiente de estresse foram valores inferiores aos obtidos pelos genótipos que foram submetidos à alta adubação, evidenciando a deficiência de N, o que limita a qualidade nutricional do feijão comum. Pesquisadores trabalham em busca de genótipos que sejam capazes de absorver maior quantidade de $\mathrm{N}$ a ela oferecida e transferi-lo aos grãos, pois essa característica é essencial para os genótipos de feijão comum utilizados na agricultura de baixos insumos. 
Tabela 2 - Médias dos teores de nitrogênio (N), e de proteína bruta(PB) presentes nos grãos de $\mathbf{4 0}$ genótipos de feijão cultivados em terras altas, na região sul do Estado do Tocantins, Gurupi, TO, na entressafra de 2010

\begin{tabular}{|c|c|c|c|c|}
\hline \multirow{2}{*}{ Genótipos } & \multicolumn{2}{|c|}{ NITROGÊNIO (\%) } & \multicolumn{2}{|c|}{ PROTEÍNA BRUTA(\%) } \\
\hline & Baixo N & Alto N & Baixo N & Alto N \\
\hline Aporé & $2,65 \mathrm{~dB}$ & $4,11 \mathrm{aA}$ & $16,56 \mathrm{eB}$ & $25,72 \mathrm{aA}$ \\
\hline BRS Esplendor & $2,69 \mathrm{~dB}$ & $3,47 \mathrm{bA}$ & $16,81 \mathrm{eB}$ & $21,69 \mathrm{bA}$ \\
\hline BRS Grafite & $2,88 \mathrm{~dB}$ & $3,27 \mathrm{cA}$ & $18,00 \mathrm{~dB}$ & $20,44 \mathrm{cA}$ \\
\hline BRS Marfim & $2,94 \mathrm{cB}$ & 4,11 aA & $18,38 \mathrm{cB}$ & $25,70 \mathrm{aA}$ \\
\hline BRS Pontal & $3,05 \mathrm{cA}$ & $2,46 \mathrm{fB}$ & $19,06 \mathrm{cA}$ & $15,40 \mathrm{fB}$ \\
\hline BRS Radiante & $3,22 \mathrm{bA}$ & $2,75 \mathrm{eB}$ & $20,13 \mathrm{bA}$ & $17,20 \mathrm{eB}$ \\
\hline BRS Requinte & $2,41 \mathrm{eB}$ & $2,55 \mathrm{fA}$ & $15,06 \mathrm{fB}$ & $15,97 \mathrm{fA}$ \\
\hline BRSMGMajestoso & $3,04 \mathrm{cA}$ & $2,97 \mathrm{~dB}$ & $19,00 \mathrm{cA}$ & $18,54 \mathrm{~dB}$ \\
\hline CNFC 10406 & $2,75 \mathrm{cB}$ & $3,04 \mathrm{cA}$ & $17,19 \mathrm{eB}$ & $19,00 \mathrm{dA}$ \\
\hline CNFC 10429 & $2,97 \mathrm{cB}$ & $3,01 \mathrm{dA}$ & $18,56 \mathrm{cB}$ & $18,81 \mathrm{dA}$ \\
\hline CNFC 10432 & $2,98 \mathrm{cB}$ & $3,24 \mathrm{cA}$ & $18,63 \mathrm{cB}$ & $20,26 \mathrm{cA}$ \\
\hline CNFC 10467 & $3,20 \mathrm{bB}$ & $3,28 \mathrm{cA}$ & $20,00 \mathrm{bB}$ & $20,47 \mathrm{cA}$ \\
\hline CNFC 10470 & $2,99 \mathrm{cB}$ & $3,34 \mathrm{cA}$ & $18,69 \mathrm{cB}$ & $20,84 \mathrm{cA}$ \\
\hline Diamante Negro & $3,04 \mathrm{cB}$ & $4,03 \mathrm{aA}$ & $19,00 \mathrm{cB}$ & $25,19 \mathrm{aA}$ \\
\hline Horizonte & $2,46 \mathrm{eB}$ & $2,75 \mathrm{eA}$ & $15,38 \mathrm{fB}$ & $17,20 \mathrm{eA}$ \\
\hline IAC Alvorada & $3,37 \mathrm{bB}$ & $3,38 \mathrm{bA}$ & $21,06 \mathrm{bB}$ & $21,12 \mathrm{bA}$ \\
\hline IAC Boreal & $3,15 \mathrm{bA}$ & $2,74 \mathrm{eB}$ & $19,69 \mathrm{bA}$ & $17,14 \mathrm{eB}$ \\
\hline IAC Centauro & $3,40 \mathrm{bA}$ & $2,86 \mathrm{~dB}$ & $21,25 \mathrm{bA}$ & $17,87 \mathrm{~dB}$ \\
\hline IAC Diplomata & 3,18 bB & $3,22 \mathrm{cA}$ & $19,88 \mathrm{bB}$ & $20,10 \mathrm{cA}$ \\
\hline IAC Carioca Eté & $289 \mathrm{~dB}$ & $3,05 \mathrm{cA}$ & $18,06 \mathrm{~dB}$ & $19,10 \mathrm{dA}$ \\
\hline IAC Galante & $2,83 \mathrm{dA}$ & $2,77 \mathrm{eB}$ & $17,69 \mathrm{dA}$ & $17,31 \mathrm{eB}$ \\
\hline IAC Carioca Tybatã & $3,10 \mathrm{cA}$ & $2,32 \mathrm{fB}$ & $19,38 \mathrm{cA}$ & $14,51 \mathrm{fB}$ \\
\hline IAC Una & $2,65 \mathrm{~dB}$ & $2,69 \mathrm{eA}$ & $16,56 \mathrm{eB}$ & $16,84 \mathrm{eA}$ \\
\hline IPR 139 & $2,83 \mathrm{~dB}$ & $3,11 \mathrm{cA}$ & $17,69 \mathrm{~dB}$ & $19,44 \mathrm{cA}$ \\
\hline IPR Chopim & $1,93 \mathrm{fB}$ & $2,83 \mathrm{eA}$ & $12,06 \mathrm{fB}$ & $17,61 \mathrm{eA}$ \\
\hline IPR Colibri & $2,46 \mathrm{eB}$ & $3,01 \mathrm{dA}$ & $15,38 \mathrm{fB}$ & $18,81 \mathrm{dA}$ \\
\hline IPR Corujinha & $4,22 \mathrm{aA}$ & $3,61 \mathrm{bB}$ & $26,38 \mathrm{aA}$ & $22,57 \mathrm{bB}$ \\
\hline IPR Eldorado & $2,91 \mathrm{cB}$ & $3,59 \mathrm{bA}$ & $18,19 \mathrm{cB}$ & $22,46 \mathrm{bA}$ \\
\hline IPR Gralha & $2,88 \mathrm{~dB}$ & $3,13 \mathrm{cA}$ & $18,00 \mathrm{~dB}$ & $19,58 \mathrm{cA}$ \\
\hline IPR Juriti & $3,10 \mathrm{cA}$ & $3,10 \mathrm{cB}$ & $19,38 \mathrm{cA}$ & $19,36 \mathrm{cB}$ \\
\hline IPR Saracura & $2,95 \mathrm{cB}$ & $3,42 \mathrm{bA}$ & $18,44 \mathrm{cB}$ & $21,36 \mathrm{bA}$ \\
\hline IPR Siriri & $3,18 \mathrm{bA}$ & $2,64 \mathrm{eB}$ & $19,88 \mathrm{bA}$ & $16,52 \mathrm{eB}$ \\
\hline IPR Tangará & $3,23 \mathrm{bA}$ & $2,73 \mathrm{eB}$ & $20,19 \mathrm{bA}$ & $17,07 \mathrm{eB}$ \\
\hline IPR Tiziu & $2,73 \mathrm{~dB}$ & $2,80 \mathrm{eA}$ & $17,06 \mathrm{eB}$ & $17,49 \mathrm{eA}$ \\
\hline Jalo Precoce & $3,01 \mathrm{cA}$ & $2,97 \mathrm{~dB}$ & $18,81 \mathrm{cA}$ & $18,59 \mathrm{~dB}$ \\
\hline Princesa & $2,76 \mathrm{dA}$ & $2,35 \mathrm{fB}$ & $17,25 \mathrm{eA}$ & $14,70 \mathrm{fB}$ \\
\hline Pérola & $2,87 \mathrm{~dB}$ & $3,38 \mathrm{bA}$ & $17,94 \mathrm{cB}$ & $21,16 \mathrm{bA}$ \\
\hline Safira & $2,94 \mathrm{cB}$ & $3,17 \mathrm{cA}$ & $18,38 \mathrm{cB}$ & $19,84 \mathrm{cA}$ \\
\hline Uirapuru & $2,75 \mathrm{~dB}$ & $3,48 \mathrm{bA}$ & $17,19 \mathrm{eB}$ & $21,74 \mathrm{bA}$ \\
\hline VC 3 & $2,71 \mathrm{~dB}$ & $2,88 \mathrm{dA}$ & $16,94 \mathrm{eB}$ & $17,99 \mathrm{dA}$ \\
\hline Média & $2,93 \mathrm{~B}$ & $3,10 \mathrm{~A}$ & 18,33 B & $19,39 \mathrm{~A}$ \\
\hline $\mathrm{CV}(\%)$ & & 4,86 & & 4,86 \\
\hline
\end{tabular}

Quanto ao ambiente de alto nível de nitrogênio, constatou-se a formação de seis grupos estatísticos (Tabela 2), sendo que o grupo de maior teor de $\mathrm{N}$ nos grãos foi constituído por três genótipos variando de 4,03 a 4,11\%. A eficiência de uso de $\mathrm{N}$ vem sendo identificada como 
característica do genótipo atribuída a processos morfológicos, fisiológicos e bioquímicos que ocorrem nas plantas, em interação com fatores externos, como clima, solo, fertilizantes e práticas de manejo (SAMBORSKI et al., 2008). O segundo grupo com sete genótipos, o terceiro com onze genótipos, o quarto grupo com seis genótipos e o quinto com nove genótipos, apresentando teores variando de 3,38 a 3,61\%, 3,05 a 3,34\%, 2,86 a 3,01\% e 2,64 a 2,82\%, respectivamente. $\mathrm{O}$ grupo com menor teor de $\mathrm{N}$, no grão, foi constituído por quatro genótipos variando entre 2,32 a 2,55\% (Tabela 2).

Decompondo cada genótipo dentro dos ambientes (alto e baixo níveis de $\mathrm{N}$ ), constatouse que 27 dos 40 genótipos respondem ao incremento do teor de nitrogênio nos grãos de feijão comum com a melhoria do ambiente, ou seja, com o aumento da dose do nutriente (Tabela 2). Isso já era esperado, pois, em muitos sistemas de produção, a disponibilidade de nitrogênio é quase sempre fator limitante, influenciando o crescimento da planta mais do que qualquer outro nutriente. $\mathrm{O}$ nitrogênio, também é considerado um elemento essencial para as plantas, pois está presente nacomposição das mais importantes biomoléculas, tais como ATP, NADH, NADPH, clorofilas, proteínas e inúmeras enzimas (HARPER, 1994).

Entretanto, para 13 dos 40 genótipos avaliados, o incremento do nutriente não resultou, necessariamente, em maiores teores de $\mathrm{N}$ nos grãos, provavelmente, devido ao fato de alguns genótipos não responderem de forma positiva à melhoria do ambiente, ou seja, com o aumento da adubação, estas plantas passam a estocar o $\mathrm{N}$ em suas folhas, não o traslocando, na totalidade, para os grãos na fase de enchimento de grãos, resultando no consumo de luxo conforme o relatado por Epstein eBloom (2004). As plantas de feijão comum que conseguem absorver os nutrientes e transferi-lo para o grão, foram consideradas eficientes, tornando-se superiores aos demais genótipos avaliados. A qualidade nutricional dos grãos colhidos pode nortear a obtenção de um produto rentável, trazendo benefícios tanto para quem o produz, quanto para quem o consome, pelo falto de esse grão possuir alto valor protéico (Tabela 2).

Analisando o teor de proteína bruta nos grãos dos 40 genótipos, no ambiente de baixo nível de nitrogênio (Tabela 2), observa-se a formação de seis grupos estatísticos, sendo que o de maior teor foi constituído apenas pelo cultivar IPR Corujinha com 26,38\%, valor superior aos encontrados por Gomes Júnior e SÁ (2010) que encontraram valores de 24,1\% e 22,9\%, respectivamente.

Deve-se ressaltar que esse cultivar IPR Corujinha tem potencial para o cultivo de pequenos agricultores, uma vez que estes dispõem de poucos recursos financeiros para investir em adubação para a produção do feijoeiro comum. Dessa forma, produziriam grãos com excelente fonte de proteína e vitaminas, de alta qualidade nutricional, mesmo sendo cultivados em ambiente de baixa dose de N. Furtini et al. (2006) observaram, em 100 linhagens de feijão comum cultivadas em diferentes ambientes, diferença na tolerância à baixa disponibilidade de $\mathrm{N}$ e/ou a resposta ao $\mathrm{N}$ aplicado, e como o feijão é um dos alimentos básicos da dieta da população brasileira, deve-se ter a preocupação em produzir um produto com qualidade e pouco gasto com adubação nitrogenada.

O segundo grupo com oito genótipos, o terceiro com quatorze genótipos, o quarto grupo com cinco genótipos e o quinto com oito genótipos, apresentaram teores de $\mathrm{N}$ variando de 19,69 a 21,25 \%,18,19 a 19,38\%,17,69 a 18,06\% e 16,56 a 17,19, respectivamente. O grupo com menor teor de proteína bruta nos grãos foi constituído por quatro genótipos variando entre 12,06 a 15,38\%. Em cultivares e linhagens de feijão adaptadas às condições edafoclimáticas brasileiras, foram relatados teores de proteína de 17 a 23,8\% (LEMOS et al., 2004). 
Quanto ao ambiente de alto nível de nitrogênio, constatou-se a formação de seis grupos estatísticos (Tabela 2),sendo que o primeiro foi constituído por três genótipos, com valores variando de 25,17 a 25,72\%, sendo superiores aos genótipos de feijão relatados na literatura com elevados teores de proteína bruta, que são, Rosinha - G2 (ANTUNES et al., 1995), Goiano Precoce (DALLA CORTE et al., 2003), variando entre 23 e 25,77\%. Evidenciando que a adubação nitrogenada promove acréscimos no teor proteico em grãos de feijão (SILVA et al., 2006; FARINELLI E LEMOS, 2010).Os demais grupos apresentaram valores próximos aos valores encontrados por Gomes Junior et al. (2005), nos grãos da cultivar IAC Carioca, em média 20,8\%.

O segundo grupo com sete genótipos (Pérola, Uirapuru, BRS Esplendor, IAC Alvorada, IAC Saracura, IPR Corujinha e IPR Eldorado), o terceiro com nove genótipos (BRS Grafite, IPR 139, Safira, IPR Juriti, IAC Diplomata, IPR Gralha, , CNFC 10432, CNFC 10470 e CNFC 10467), o quarto com oito (CNFC 10406, CNFC 10429 , BRSMG Majestoso, IAC Centauro, IAC Carioca Eté, Jalo Precoce, IPR Colibri e VC3) o quinto com nove genótipos (BRS Radiante, Horizonte, IAC Boreal, IPR Tangará, IPR Siriri, IAC Galante, IAC Una, IPR Chopim e IPR Tiziu), apresentaram teores variando de 21,12 a $22,72 \%, 19,36$ a 20,44\%, 17,87 a 19,10\% e 16,57 a 17,49\%, respectivamente. O grupo com menor teor de proteína no grão foi constituído por quatro genótipos (BRS Pontual, IAC Carioca Eté, BRS Requinte e Princesa) variando entre 14,51a 15,97\% (Tabela 2).Os teores de proteína bruta encontrados em grãos de feijão comum variaram de 18 a 31\%, dependendo do genótipo avaliado (ANTUNES et al., 1995; DALLA CORTE et al., 2003).

Decompondo cada genótipo dentro dos ambientes (alto e baixo teores de N), constatouse que 27 dos 40 genótipos respondem a adubação com o incremento do teor de nitrogênio nos grãos, resultando em maiores teores de proteína bruta (Tabela 2), o que já era esperado, pois o nitrogênio está diretamente relacionado à porcentagem de proteína bruta dos grãos. Andrade et al. (2004) perceberam que o teor de proteínas em grãos de feijão comum foi diretamente relacionado com a adubação nitrogenada (Tabela 2).

Entretanto, para 13 dos 40 genótipos avaliados, o incremento do nutriente não resultou necessariamente em maiores teores de $\mathrm{N}$ nos grãos e, consequentemente, na proteína bruta nos grãos. Maia et al. (2005) afirmam que o teor de proteínas do feijão pode ser alterado através da adubação utilizada. Os valores obtidos no ambiente de alta dose nitrogenada, nos mostra a eficiência na aplicação de fertilizantes nitrogenados, o que resulta em maior qualidade nutricional dos grãos. Barbosa Filho (1987) ressalta que a adubação nitrogenada,proporciona acréscimo no teor de proteína nos grãos.

Diversos fatores ambientais podem comprometer a eficiência do $\mathrm{N}$ nos genótipos, pois, para que este seja metabolizado, ocorrem inúmeros processos. Assim, percebe-se que sob estresse a atividade das enzimas do metabolismo do $\mathrm{N}$ torna-se limitada, afetando o catabolismo de aminoácidos, proteínas e outros compostos nitrogenados. O que torna importante o uso de fertilizantes nitrogenados para que, assim, possam ser bem aproveitados pelas plantas, resultando em maior qualidade nutricional de seus grãos. 


\section{Conclusões}

Existe variabilidade genética entre os genótipos de feijão comum, quanto à qualidade protéica.

O cultivar IPR Corujinha é recomendado quanto a seu teor de proteína bruta para ser cultivado e consumido por agricultores com pouca tecnologia, pois é capaz de apresentar boa qualidade nutricional mesmo cultivado em baixo nível de Nitrogênio.

Os cultivares Aporé, BRS Marfim e Diamante Negro apresentam elevado teor protéico quando cultivados em ambiente de alto nível de Nitrogênio.

\section{Referências}

AFONSO, R. J; ARF, O. COSTA, D. S.; BARBOSA R. M; BUZETTI S; SÁ M. E; RODRIGUES, R. A. F. Combinações de fontes de nitrogênio no desenvolvimento e rendimento do feijoeiro Pesquisa Agropecuária Tropical, Goiânia, v.41, n.3,4, p.391$398,2011$.

ANDRADE, C. A. B.; PATRONI, S. M. S.; CLEMENTE, E.; SCAPIM, C. A. Produtividade e qualidade nutricional de cultivares de feijão em diferentes adubações. Ciência e Agrotecnologia, Lavras,v. 28, n. 5, p. 1077-1086, 2004.

ANTUNES, P.L.; BILHALVA, A. B.; ELIAS, M.C.; SOARES, G.J.D.Valor nutricional de feijão (Phaseolus vulgaris L.), cultivares Rico 23, Carioca, Piratã-1 e Rosinha-G2. Revista Brasileira de Agrociência, Pelotas, v. 1, n. 1, p.12-18, 1995.

BARBOSA FILHO, M.P. Nutrição e adubação do arroz: sequeiro e irrigado. Potafós,. (Boletim Técnico 9), Piracicaba, 129 p. 1987.

BORDIN, L.C.; COELHO, C.M.M.; SOUZA, C. A.; ZILIO, M. Diversidade genética para a padronização do tempo e percentual de hidratação preliminar ao teste de cocção de grãos de feijão. Ciência e Tecnologia dos Alimentos, Campinas, v. 30, n. 4, p.890896, 2010.

CANTARELLA, H. Nitrogênio. In: NOVAIS, R.F.; ALVAREZ V., V.H.; BARROS, N.F.; CANTARUTTI, R.B.; NEVES, J.C.L. (Ed.) Fertilidade do solo.Sociedade Brasileira de Ciência do Solo, Viçosa, p. 375-470, 2007.

BURATTO, J. S.; MODA CIRINO, V.; SCHOLZ, M. B. S.; LANGAME, D.E.M.; FONSECA JUNIOR, N. S.; PRETÉ, C.E.C. Variabilidade genética e efeito do ambiente para o teor de proteína em grãos de feijão. Acta ScientiarumAgronomy, Maringá, v.31, n.4, p. 593-597, 2009. 
CONAB-COMPANHIA NACIONALDEABASTECIMENTO.Acompanhamento da safra Brasileira: grãos décimo segundo levantamento, setembro 2014, Brasilia: Conab, p. 111. Disponível em: < http://www.conab.gov.br>. Acesso em: 29 de Setembro de 2014.

DALLA CORTE,A.; MODA-CIRINO,V.; SCHOLZ,M.B. S.; Destro D. Environment effect on grain quality in early common bean cultivars and lines. Crop Breeding and Applied Biotechnology, Maringá,v. 3, n. 3, p. 193-202, 2003.

DEL PINO, V. M. H.; LAJOLO, M. F. Efectoinhibitorio de los taninos delfrijol carioca (PhaseolusvulgarisL.) sobre ladigestibilidad de lafaseolina por dos sistemas multienzimáticos. Ciência e Tecnologia de Alimentos, Campinas, v. 23, n. 01, p. 49-53, 2003.

EPSTEIN, E.; BLOOM, A.J. Nutrição e Crescimento. In: Nutrição mineral de plantas: princípios e perspectivas. Editora Planta, Londrina, p. 251-284, 2004.

FAGAN, E. B.; MEDEIROS, S. L.P.; MANFRON, P.A.; CASAROLI, D.; SIMON J.; NETO, D. D.; VAN LIER, Q.J.; SANTOS, O. S.; MULLER, L. Fisiologia da fixação biológica do nitrogênio em soja - revisão. Revista da FZVA, Uruguaiana, v.14, n.1, p.89106, 2007.

FAGERIA, N. K.; BALIGAR, V. C. Enhancing nitrogen use efficiency in crop plants. Advances in Agronomy, New York, v. 88, p. 97-185, 2005.

FAGERIA, N. K.; STONE, L. F.; SANTOS, A. B. Manejo da fertilidade do solo para o arroz irrigado. Embrapa Arroz e Feijão, Santo Antônio de Goiás, p.250, 2003.

FARINELLI, R.; LEMOS, L. B. Produtividade, eficiência agronômica, características nutricionais e tecnológicas do feijão adubado com nitrogênio em plantio direto e convencional. Bragantia, Campinas, v.69, n.1, p.165-172, 2010.

FERREIRA, D. F. Sisvar: um sistema computacional de análise estatística. Ciência e Agrotecnologia, Lavras, v. 35, p. 1039-1042, 2011.

FOOD AND AGRICULTURE ORGANIZATION OFTHE UNITED NATIONS (FAO). Disponível em: <http://www.fao.org/rice2004>. Acesso em 21 de Setembro de 2014.

FROTA, K. M. G.; MORGANO, M. A.; SILVA, M. G.; ARAÚJO, M. A. M.; MOREIRA-ARAÚJO, R. S. R. Utilização da farinha de feijão-caupi (Vigna unguiculata L.) na elaboração de produtos de panificação. Ciência e Tecnologia de Alimentos, Campinas, v. 30, p. 44-50, 2010. 
FURTINI,I.V.; PATTO R, M. A.; ABREU, A. F. B.; FURTINI NETO, A. E. Resposta diferencial de linhagens de feijoeiro ao nitrogênio. Ciência Rural, Santa Maria,v. 36, n. 6, p. 1696-1700, 2006.

GOMES JUNIOR, F. G. G.; LIMA, E. R.; LEAL, A.J.F.; SÁ, M.E.; HAGA, K. I.Teor de proteína em grãos de feijão em diferentes épocas e doses de cobertura nitrogenada. Acta ScientiarumAgronomy, Maringá,v. 27, n. 3, p. 455-459, 2005.

GOMES JÚNIOR, F.G.; SÁ, M.E. Proteína e qualidade de sementes de feijão (Phaseolus vulgaris $\mathrm{L}$.) em função da adubação nitrogenada em plantio direto. Revista Brasileira de Sementes, Brasília, vol. 32, n. 1, p. 34-44, 2010.

HARPER,J.E. Nitrogen metabolism. In: BOOTE, K.J.; BENNETT.J.M.; SINCLAIR, T.R.Physiology and determination of crop yield. ASA/CSSA/SSSA. Madison, p.285302, 1994.

LANARO, N.; BAJAY, L.G.; QUEIROZ, V.M. P.; PINTO, R.C.S.; LEITÃO, I.G.A.; LESSIO, B.C.; AUGUSTO, P.E.D. Determinação de propriedades físicas do feijão fradinho. Revista Brasileira de Produtos Agroindustriais, Campina Grande, v.13, n.1, 2011.

LEMOS, L.B.; OLIVEIRA, R.S.; PALOMINO, E.C.; SILVA, T.R.B. Características agronômicas e tecnológicas de genótipos de feijão do grupo comercial carioca. Pesquisa Agropecuária Brasileira, Brasília,v.39, n.4, p.319-326, 2004.

MAIA, C. E.; MORAIS, E. R. C. DE.; PORTO FILHO, F. de Q.; GUEYI, H. R.; MEDEIROS, J. F. Teores foliares de nutrientes em meloeiro irrigado com águas de diferentes salinidades. Revista Brasileira de Engenharia Agrícola e Ambiental, Campina Grande,v.9, p.292-295, 2005.

MARENCO, R. A.; LOPES, N. F. Fisiologia Vegetal: fotossíntese, respiração, relações hídricas e nutrição mineral. UFV, Viçosa, p.486, 2009.

PEREIRA, L. S. Estudo comparativo entre faseolamina comercial e farinha de feijão como perspectiva ao tratamento da obesidade e do diabetes mellitus tipo. $200872 \mathrm{f}$. Dissertação (Mestrado em Agroquímica) - Universidade Federal de Lavras, Lavras, 2008.

PERINA, E. F.; CARVALHO, C. R. L.; CHIORATO, A. F.; c CARBONELL, S. A. M. Avaliação da estabilidade e adaptabilidade de genótipos de feijoeiro (Phaseolus vulgaris L.) baseada na análise multivariada da "performance" genotípica. Ciência e Agrotecnologia, Lavras,.v.34, n. 2, p. 398-406, 2010.

PESSOA, A. C. S. Atividade de nitrogenase e redutase do nitrato e produtividade do feijoeiro em resposta a adubação com molibdênio e fósforo. 1998. 1998f. Tese (Doutorado em solos e nutrição de plantas) - Universidade Federal de Viçosa, Viçosa,1998. 
PIRES, C. V.; OLIVEIRA M. G. A.; ROSA, J. C.; COSTA, N. M. B. 2006. Qualidade nutricional e escore químico de aminoácidos de diferentes fontes proteicas. Ciências $\mathbf{e}$ Tecnologia de Alimentos, Campinas, v.26, n.1, p.179-187, 2006.

ROSOLEM, C. A.; MARUBAYASHI, O.M. Seja o doutor do seu feijoeiro In: Encarte do Informações Agronômicas, Piracicaba,n.68, p.1-16, 1994.

RIBEIRO, N. D.; LONDERO, P. M. G.; CARGNELUTTI FILHO, A.; JOST, E.; POERSCH, N. L.; MALLMANN, C. A. 2007a. Composição de aminoácidos de cultivares de feijão e aplicações para o melhoramento genético. Pesquisa Agropecuária Brasileira, Brasília, v. 42, n. 10, p. 1393-1399, 2007.

RIBEIRO, N. D. JOST, E.; CERUTTI, T.; MAZIEIRO, S. M.; POERSCH, N. L. Composição de microminerais em cultivares de feijão e aplicações para o melhoramento genético. Bragantia, Campinas, v. 67, p. 267-273, 2008.

SALGADO, F. H. M. Efeito do nitrogênio na produtividade de grãos e qualidade fisiológica de sementes de genótipos de feijão comum. 2011. 55f. Dissertação (Mestrado em Produção Vegetal) - Universidade Federal do Tocantins, Gurupi, 2011.

SALGADO, F. H. M.; FIDELIS, R. R.; CARVALHO, G. L; SANTOS, G. R. dos; CANCELLIER, E. L.; SILVA, G. F. Comportamento de genótipos de feijão, no período da entressafra, no sul do estado de Tocantins. Bioscience Journal, Uberlândia, v.27, n. 1, p.52-58, 2011.

SAMBORSKI, S.; KOZAK, M.; AZEVEDO, R.A. Does nitrogen uptake affect nitrogen uptake efficiency, or vice versa. Acta Physiologia e Plantarum, Heidelberg, v.30, p.419420, 2008.

SILVA, T. R. B.; LEMOS, L. B.; TAVARES, C. A. Produtividade e característica tecnológica de grãos em feijoeiro adubado com nitrogênio e molibdênio. Pesquisa Agropecuária Brasileira, Brasília, v.41, n. 5, p.739-745, 2006.

YASUHARA T., NOKIHARA K. High-throughput analysis of total nitrogen content that replaces the classic Kjeldahl method. Journal of agricultural and food chemistry, Easton, v.49, n.10, p.4581-4583, 2001. 